\title{
Drought Impacts on Grassland Productivity: The Role of Plant-Soil Feedbacks ${ }^{\dagger}$
}

\author{
Kamrul Hassan *, Yolima Carrillo and Uffe N. Nielsen \\ Hawkesbury Institute for The Environment, Western Sydney University, Richmond 2753, Australia; \\ y.carrillo@westernsydney.edu.au (Y.C.); u.nielsen@westernsydney.edu.au (U.N.N.) \\ * Correspondence: kamrul.hassan@westernsydney.edu.au \\ + Presented at the third International Tropical Agriculture Conference (TROPAG 2019), Brisbane, Australia, \\ 11-13 November 2019.
}

Published: 20 January 2020

\begin{abstract}
Drought influences pasture productivity with potentially severe impacts on livestock. However, not all plant species are impacted equally indicating that plant community composition can be managed to improve resistance to drought. We conducted a plant-soil feedback (PSF) experiment to assess impacts of drought at the species and community level. We grew twelve plant species representing C3 and C4 grasses, forbs and legumes in monocultures and in 4-species mixtures (one from each functional group) in soils with a legacy of ambient or drought (5 years) conditions for two generations. We measured plant biomass in the second generation to calculate PSF. Species with positive PSF under drought are likely to be more resistant to drought than those with negative PSF. Under ambient rainfall PSFs were generally negative for C3 grasses, positive for C4, forbs and legumes. Drought promoted negative PSFs in C3 grasses and forbs, but positive PSFs were observed in $\mathrm{C} 4$ grasses and legumes. These results indicate that $\mathrm{C} 3$ grasses and forbs are likely to be sensitive to drought while $\mathrm{C} 4$ grasses and legumes will be less negatively impacted by drought due to changes in PSFs. PSFs at the community level were positive at the community level under ambient but shifted towards neutral under drought indicating that drought may destabilize plant communities. Our results indicate that presence of $\mathrm{C} 4$ grasses and legumes may reduce drought impacts providing a tool for future pasture management for healthy livestock production in Australian rangeland.
\end{abstract}

Keywords: Plant-soil feedbacks; drought legacy; plant functional group; plant community dynamics

Author Contributions: K.H. and U.N.N. conceived and designed the experiment. K.H. conducted the experiment. K.H. finished the first draft of manuscript. Both U.N.N. and Y.C. reviewed the manuscript and made significant contribution for further development.

Acknowledgments: This study supported by Australian Commonwealth Government to Kamrul Hassan for his PhD study in Western Sydney University.

Conflicts of Interest: The authors declare no conflict of interest.

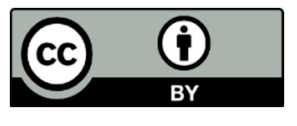

(C) 2020 by the authors. Licensee MDPI, Basel, Switzerland. This article is an open access article distributed under the terms and conditions of the Creative Commons Attribution (CC BY) license (http://creativecommons.org/licenses/by/4.0/). 